\title{
Article \\ Sustainability, Efficiency, and Competitiveness in Rail Mobility: The ADIF-Spain Case Study
}

\author{
José Ramón García-Aranda ${ }^{1}$, Raquel Ortega-Lapiedra ${ }^{1,2, *(D)}$ and Jara Bernués-Olivan ${ }^{3}$ \\ 1 Department of Management, University of Zaragoza, 50009 Zaragoza, Spain; jrgarciaaranda@gmail.com \\ IEDIS, University of Zaragoza, 50018 Zaragoza, Spain \\ 3 Department of Marketing, ESIC Business \& Marketing School, 50012 Zaragoza, Spain; jara.bernues@esic.edu \\ * Correspondence: rortega@unizar.es
}

Citation: García-Aranda, J.R.; Ortega-Lapiedra, R.; Bernués-Olivan, J. Sustainability, Efficiency, and Competitiveness in Rail Mobility: The ADIF-Spain Case Study. Sustainability 2021, 13, 8977. https://doi.org/ $10.3390 /$ su13168977

Academic Editor: Marilisa Botte

Received: 3 June 2021

Accepted: 3 August 2021

Published: 11 August 2021

Publisher's Note: MDPI stays neutral with regard to jurisdictional claims in published maps and institutional affiliations.

Copyright: (c) 2021 by the authors. Licensee MDPI, Basel, Switzerland. This article is an open access article distributed under the terms and conditions of the Creative Commons Attribution (CC BY) license (https:/ / creativecommons.org/licenses/by/ $4.0 /)$.

\begin{abstract}
This work aims to propose alternatives to the EFQM (European Foundation for Quality Management) Model from the perspectives of sustainability, efficiency, and competitiveness, with an application to the railway sector in Spain. Concerning improvement factors, a retroactive analysis is based on a second-degree confirmatory factorial analysis, suggesting a new grouping of factors. With respect to the transformation process, a systemic proposal of seven cross-cutting elements (Integral Framework for Transformation into Outstanding Organizations) is presented, providing a sequence of reflection and action initiatives to successfully address the current environmental sustainability, efficiency, and competitiveness challenges in the railway sector through a case study, ADIF (Administrador de Infraestructuras Ferroviarias). The proposal for this Integrated Framework for The Transformation of Organizations is carried out to consolidate the EFQM Model, not only as a management evaluation tool, but also as a quality of management and sustainability instrument, increasing its role as a driving mechanism for actions that generate an effective improvement and transformation in an organization dedicated to mobility. The confirmation of all the hypotheses related to the relationship between Leadership and Strategy, on the one hand explanations., and People, Alliances and Resources, and Processes on the other, along with the four Criteria of Results (People, Clients, Society, and Key Results), allows for the proposal of an EFQM Model that evolves around three major constructs: Guidance, Action, and Feedback. The implications of this work focus on three areas: (1) theoretical, as it is the first analysis of this magnitude to be performed in literature; (2) research, as it opens new hypotheses for contrasting with other organizations in the sector; and (3) management, as it proposes a sustainable organizational and business model.
\end{abstract}

Keywords: mobility; sustainable business model; management quality

\section{Introduction}

The structure of the EFQM Model, designed from the outset and based on nine criteria, arose in 1991 in a specific context in which the priority was to provide an evaluation tool based on a continuous improvement cycle (Figure 1). Looking at the nine criteria, the question that arises is: to what extent is the business framework sustainable in the current economic and social scenario? Concern for quality management first arose in 1987, when a law was passed in the US Congress to promote and boost awareness of quality management and recognize those national organizations that successfully implemented quality management systems. Since then, the Malcolm Baldrige Award has been one of the greatest recognitions of excellence.

As a result of the Malcolm Baldrige Award and its impact on improving the competitiveness of the industry and other sectors in the US, 14 European multinationals created a foundation at the end of 1988 to promote Total Quality Management on the continent. Although both schemes were based on the idea of Excellence as a natural (and close) evolution of the Concept of Total Quality Management (TQM), the EFQM Model has already begun 
to show a visionary character by focusing attention on aspects beyond purely economic ones; it introduces a specific criterion on the results in a society that highlights the relevance of taking into account the environment in which the organization is located and to view it more as a group of interest [1].

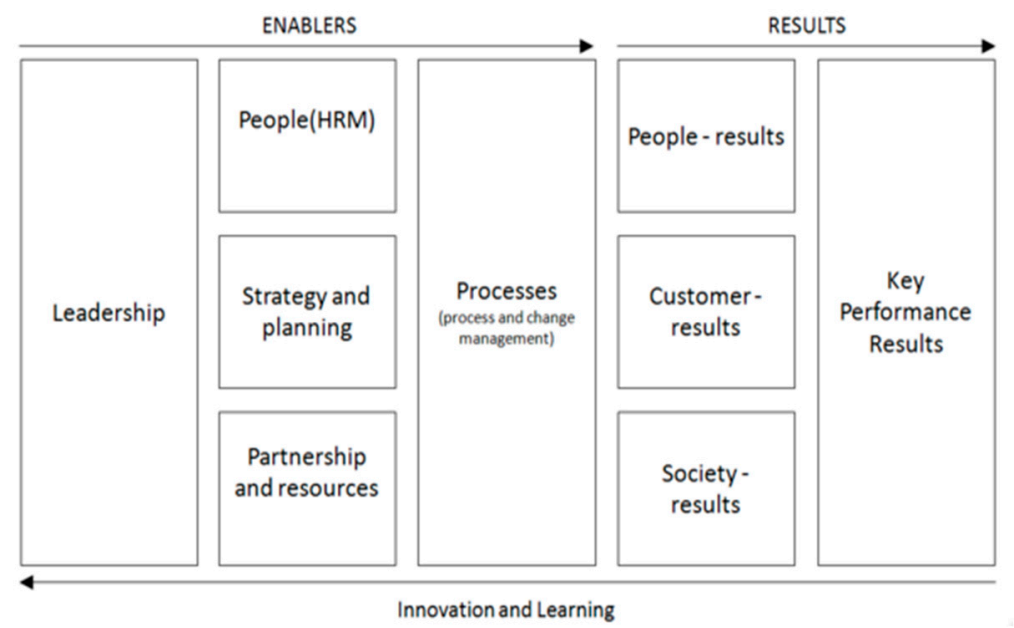

Figure 1. The EFQM model.

Social responsibility has not always been considered relevant in the business field. Until fairly recently, an organization's decisions were always interpreted from a perspective based on traditional liberalism [2]: Any activity not intended to maximize economic benefit, understood as the main responsibility of any company, was regarded as a questionable use of the organization's resources. This paradigm is considered increasingly limited, in the sense that the success of organizations is greater and more durable depending on the organization's ability to balance the key expectations of the stakeholders most important to it (within which are shareholders and regulators, customers, people, society or allies, and suppliers), thus building the concept of social enterprise based on sustainable management.

Nearly three decades have passed since the birth of the EFQM model and both the context in which it was created, and the environment of organizations have changed radically. While many of the key elements for excellent management continue to be maintained, the EFQM model is moving from being a tool for assessing or diagnosing excellence to a reference framework for transformation through management that integrates three elements-Excellence, Innovation, and Sustainability - all of which are particularly relevant factors in a public mobility organization.

The objective of this work focuses on raising alternatives to the EFQM model from a perspective of simplification and simplicity in its application and contrasting the extent to which some of the factors analyzed would work together and in what areas an organization should pay particular attention when dealing with successful processes of improvement and transformation. Concerning improvement factors, a retroactive analysis is carried out based on a second-degree confirmatory factorial analysis, suggesting a new grouping of factors. With regard to the transformation process, a systemic proposal of seven crosscutting elements (Integral Framework for Transformation into Outstanding Organizations) is presented, providing a framework for reflection and action to successfully address the challenges currently posed by environmental sustainable management.

The confirmation of all the assumptions relating to the covariance between Leadership and Strategy, on the one hand, and Persons, Alliances and Resources, and Processes on the other, along with the four Criteria Results and the restructuring of these dimensions into new criteria or factors allows for the proposal of an EFQM model that evolves around three major constructs: Guidance, Action, and Feedback.

This study is the first analysis of these features in the literature, as well as the first to contrast them with the EFQM 2020 Model and the degree of consistency and solidity of the new grouping of dimensions and/or criteria. The contributions of the article are 
threefold. First, it is intended to contribute to the existing literature in terms of adopting a holistic perspective of the EFQM model beyond a set of elements or management areas. This perspective, paradoxically, has not been adopted as widely as might be assumed, contributing to a lack of theory on the approach that remains to this day [3]. Second, the implications for managing the proposed model can be very useful by more easily articulating the areas in which management teams approach decision making strategically, tactically, or operationally. Third, it is a different starting point for the development of future research with the proposed assumptions.

These three contributions are based on the analysis of a case study of the specific railway transport sector, which is especially representative of the deployment of principles of excellence at the public level, as well as at national and international levels. The EFQM Model was practically applied to a Spanish public business entity, a reference in its sector (the railway sector) at the international level during a key time interval (2003-2011; 2018-2020). In terms of deployed management practices and results obtained, this case study offers an excellent opportunity to analyze and reflect on the management mechanisms that have enabled such positioning.

This work is structured as follows. The first section develops the conceptual framework that aims to answer the proposed research question. A simplified three-dimensional research model is designed in which different relationships between dimensions and subdimensions that invite the contrast of these relationships in terms of direct and indirect effects are identified. The second section describes the sample, the case of a company dedicated to mobility, and the design of the investigation in which the qualitative and quantitative aspects of the chosen case come together. The third section presents the main results of the hypothesis contrast proposed through structural equations, which give rise to an interesting discussion. Finally, a section regarding the theoretical, research, and management implications at the applied level concludes the work.

\section{Literature and Conceptual Framework}

One of the main motivations of many researchers, as well as numerous management professionals, is to be able to find a theoretical framework that provides satisfactory explanations regarding the reasons for which an organization succeeds as well as how it manages to maintain success over time. The lack of conclusive proposals surrounding the topic shows the complexity of such a challenge.

Since its inception, the EFQM model has sought to reflect the main causal relationships between the main areas of management of an organization from the perspective of the Facilitating Agents Criteria, the Results Criteria, or from a perspective that is between the two blocks $[4,5]$. Several previous research studies have contrasted, after analyzing the validity of the underlying theoretical model, the overall effect ratio between the Facilitating Agents Criteria and the Results Criteria [6,7]. Models are usually designed to simply represent complex realities because if reality were simple, per se, it would not be necessary to design a model on it since it could be explained on its own. The EFQM model is thus a reference of complexity, but simplification is the desired outcome in order to, among other reasons, increase its usability [8].

Although proposals have emerged in the last decade on new structures of Models of Excellence, motivated by a greater explicit nation of measurements of intangible elements [9], or an integration with other philosophies or management tools such as Six Sigma [10], or to place greater emphasis on the concept of sustainability [11] to either strengthen the alignment of initiatives within the organization [12] or to strengthen and make the level of performance visible from a competitive perspective/with world-class organizations [13], the purpose of this article is not to propose new structures but rather present alternatives to the simplification of the EFQM model. This is achieved through a process of development and contribution to existing theories.

In this sense, different proposals to simplify the EFQM model have been carried out over time. One of the most comprehensive studies carried out in this regard is [14], which 
analyzed information of more than 750 European organizations to find that Leadership and Strategy have a relationship between them of almost one to one, suggesting that both dimensions could be reduced to a single entity without any significant loss of information (the authors call it Leadership).

Different authors $[15,16]$ have defended, over time, the positive relationship between Leadership and Strategy. The role that leaders play in establishing management pillars (purpose, vision, values) and a successful roadmap to achieve organizational goals (strategy) is key [17], making leadership a catalyst for strategy. The ultimate goal of the leaders of any organization is to enhance both economic and non-economic results, link these increases to all its stakeholders, and establish an adequate balance between all of the parties involved. Moreover, this goal materializes through the strategy: the more alignment there is between it, the leaders, and the entire management structure (both in the process and project parts and in terms of resource management), the more effective the strategy will be at the results level [18].

On the other hand, the authors also propose the integration of the Criteria of People and Results into a dimension called People, as well Alliances and Resources and Processes into a dimension called Systems. Finally, Customer, Company, and Key Results are to be grouped into a single dimension called Feedback.

Based on all of the above, the Research Model proposed is part of the grouping of the nine constructs of the EFQM model into three main latent large dimensions that are in line with the proposed Comprehensive Framework:

(i) Guidance: encompasses the latent under dimensions of Leadership and Strategy;

(ii) Action: the result of the grouping of sub-dimensions Persons, Alliances and Resources, and Processes;

(iii) Feedback: includes the sub-dimensions of Results in Clients, Persons, Company, and Keys.

Regarding the relationships identified at the level of structural equations and between the different sub-dimensions, the described approach invites the contrast of the following hypotheses (direct and indirect effects) (Figure 2):

\begin{tabular}{|c|c|c|c|c|}
\hline Guidance & $\Rightarrow$ & Action & $\Longrightarrow$ & Feedback \\
\hline Leadership & & Processes & & Res $\mathrm{CL}$ \\
\hline \multirow[t]{3}{*}{ Strategy } & & People & & Res People \\
\hline & & Resources & & Res Soc \\
\hline & & & & $\operatorname{Res} \mathrm{CV}$ \\
\hline
\end{tabular}

Figure 2. Three dimensional simplified research model: Guidance, Action, and Feedback.

Hypothesis 1 (H1). The Guidance dimension is the result of the relationship between the latent constructs of Leadership and Strategy.

Hypothesis 2 (H2). The Action dimension is the result of the relationship between latent constructs of People, Resources, and Processes.

Hypothesis 3 (H3). The Feedback dimension is the product of the relationship between latent constructs of all Results Criteria.

\section{Methods and Results}

The choice of the Spanish Railway Infrastructure Manager (ADIF) was due to multiple key factors from which its degree of representativeness is extracted. First, it is one of the pioneering public organizations that began working with the EFQM model when it was 
first created (through the Total Quality Plan deployed at RENFE, when it included what is now ADIF). Second, it is the first Spanish organization to win the highest European Quality Prize award in the Public Sector category, which it did so with the High-Speed Train Unit in 1998.

Following the segregation of RENFE and the creation of ADIF as an independent entity in 2005, the commitment to excellence at the global level for the whole organization was then reinforced in 2006 at the first strategic level. This allowed the organization to obtain the highest level of recognition EFQM (Seal of Excellence +500 ) just a few months later, the first in its sector at the international level to do so.

In addition to the aspects cited in the choice of case study, it highlights the fact that one of the researchers was part of the team of official accredited evaluators of EFQM. This detail negatively affects the nature of a single case in terms of accessibility to the level of detail of the analysis carried out.

The proposed model requires, from an analytical point of view, a different approach of the hypotheses on the Confirmatory Factorial Model from the existing previous model, which is made for each of the nine constructs that make up the EFQM model and in which the individual constructs are considered (Leadership, Strategy, People, Alliances and Resources, Processes, Client Results, Results People, Company Results, and Key Results). In line with the consolidation of the EFQM model as a more active instrument in the dynamics of transformation of organizations, the structure of this 2020 Model is articulated around three major dimensions: Guidance, Action, and Feedback. Here, it is important to confirm that since very recently, 1 January 2021, a new EFQM model articulated around seven criteria is mandatory in Spain. Thus, despite the fact that there is not yet sufficient theoretical support on how this integrated deployment of seven criteria generates outstanding results in its different dimensions, it is relevant to investigate more in-depth the hypotheses and the predictive power of the new model in different sectors, different geographical contexts, and different temporal moments.

The research methodology is based on the notion that the objective of the study is to confirm the theoretical dimensions that make up the EFQM Model, applied to the case to propose an evolved model of integral management. The structure of the available data matrix is analyzed using factor analysis (Exploratory Factor Analysis (EFA) and a Confirmatory Factor Analysis (CFA)).

First, an analysis of the relationships between the different sub-criteria of the EFQM model has been carried out, identifying the specific sub-criteria on which it is to act, to improve the results for each interest group. This implies analyzing, through AFE, the relational structure among the items and their respective latent dimensions (Leadership, Strategy, Alliances and Resources, People, and Processes, in the role of Criteria Facilitating Agents and Results in Clients, People, Society, and Key Criteria Results)

Second, a simplified model has been identified based on the sub-criteria of the EFQM model, which allows us to carry out more precise evaluations, as well as to more properly guide the improvement in the dimensions that are simplified or grouped, confirming the constructs through AFC.

Finally, we have analyzed the structural relationships between the latent exogenous (Criteria Facilitating Agents) and endogenous (Criteria Results) constructs. In sum, the first two stages, EFA and CFA, allow us to contrast the analytical demonstration of endogenous and exogenous constructs, while the third stage, the analysis of causal relationships, allows us to contrast the exogenous and endogenous structural relationships.

The main phases followed have been the acquisition of empirical material, which includes the data base and sample composition, and the method used and the discussion of the results. With respect to the acquisition of empirical material or preparation of data for analysis the steps were as follows: identification of the initial causal model based on the theoretical framework of the research, including its graphic representation (path diagram) and the choice of the data matrix and analysis of causal relationships (covariance, which measures the linear relationship between two variables, allows for an understanding of 
the direction of the relationship between the variables, indicating, if positive, that both variables vary in the same direction, and correlation, which measures both the strength and the direction of the linear relationship between two variables and is standardized between 1 and -1 , both values being evidence of direct or inversely proportional total correlation, respectively). The modeling of structural equations is based on causal relationships in which the change in one variable is supposed to produce a change in another [19].

A database is available that includes, on 45 internal evaluations carried out in the period from 2007-2018, a matrix of $45 \times 66$ items, which requires checks of random behavior of the scores, the validity, and reliability of the construct, and the significance of the structural relationships between the variables together. The data collected in the aforementioned period include the complete collection of items of the questionnaires used (Version 2 between 2007 and 2010; Version 3 between 2011 and 2018), with some small changes derived from the passage from the EFQM model 2003 to the EFQM model 2010, and the consequent adjustment of the tool (Version 3) in which several items are deleted, performing an analysis adjusted to the absence of such data. The basis of the analysis is, therefore, the observable items that measure each of the latent constructs, in a range of 0-100 points distributed across five levels.

With respect to the method used and the discussion of results, it first implies the estimation of the research model through the choice of the estimation procedure and choosing the maximum likelihood method, since part of the assumption of normality of the data and the estimates obtained does not depend on the scale of measurement of the variables [20,21]. The discussion of results is based on the evaluation of the model. For the same, and among the wide variety of existing statistics, three goodness-of-fit indices of the model have been used: CFI (Comparative Fit Index), TLI (Tucker-Lewis Index), LR (Likelihood ratio) and, as additional indices, SRMR (Standardized Root Mean Square Residual) and CD (total coefficient of determination).

In this context, it is necessary to examine the relationships that exist in each of the subdimensions of the new model that make up the three latent dimensions described above: Guidance, Action, and Feedback. This check in the Confirmatory Factorial Analysis is key because its link results in a greater reduction between the structural relationships explicit from the Orientation to the Action dimension, and the Action dimension towards Feedback.

The data used to check the EFQM model in its previous versions have been used to verify the existence of a confirmatory relationship between the constructs and latent dimensions. Leadership and Strategy are combined under the name of a single variable or latent dimension known as Guidance. The Action dimension includes the People, Resources and Alliances, and Processes constructs. Finally, the Feedback dimension depends on the results of four constructs: Customers, People, Society, and Key Results. The process, in short, uses past data (retrospective study) to conceptualize the new vision of the EFQM model, thus opening up a wide spectrum of possibilities in future research.

This work presents the analysis of the latter dimension, Feedback, and the proposed conceptual framework in which the previous two converge, Action and Guidance.

The joint analysis of all items set to measure the latent Feedback variables (Customers, People, Society, and Key Results) shows a structure around four constructs, observing the saturation of two items in more than one latent factor and linking a single item to one of them.

Before checking with the confirmatory analysis of these integrations, an exploratory factorial analysis has been performed to observe the relationships between items and the variables of the final three dimensions (Table 1). 
Table 1. Exploratory factorial analysis: Feedback results.

\begin{tabular}{|c|c|c|c|c|}
\hline \multirow[b]{2}{*}{ Items } & \multicolumn{4}{|c|}{ Feedback } \\
\hline & $\begin{array}{c}\text { Results in People and } \\
\text { Society }\end{array}$ & $\begin{array}{c}\text { Customer and } \\
\text { Performance Results }\end{array}$ & $\begin{array}{l}\text { Learning and } \\
\text { Benchmarking }\end{array}$ & $\begin{array}{c}\text { Financial Economic } \\
\text { Results }\end{array}$ \\
\hline $\begin{array}{c}\text { P1RS (Direct } \\
\text { information society) }\end{array}$ & 0.899 & & & \\
\hline $\begin{array}{l}\text { P2RS (Society active } \\
\text { collaboration) }\end{array}$ & 0.890 & & & \\
\hline $\begin{array}{l}\text { P6RS (Social perception } \\
\text { improvement) }\end{array}$ & 0.854 & & & \\
\hline $\begin{array}{c}\text { P1RPR (Direct } \\
\text { information people) }\end{array}$ & 0.814 & & & \\
\hline $\begin{array}{l}\text { P3RPR (Security } \\
\text { satisfaction) * }\end{array}$ & 0.811 & & & \\
\hline $\begin{array}{l}\text { P2RPR (Incentives and } \\
\text { social benefits) }\end{array}$ & 0.804 & & & \\
\hline $\begin{array}{c}\text { P7RS (KPIs. vs. society } \\
\text { satisfaction) }\end{array}$ & 0.803 & & & \\
\hline $\begin{array}{l}\text { P4RS (Risk/danger } \\
\text { prevention) }\end{array}$ & 0.802 & & & \\
\hline $\begin{array}{l}\text { P4RPR (Cause and } \\
\text { effect relationship)* }\end{array}$ & 0.787 & & & \\
\hline $\begin{array}{c}\text { P3RS (Social } \\
\text { commitments) * }\end{array}$ & 0.783 & & & \\
\hline $\begin{array}{c}\text { P5RS (Environmental } \\
\text { effectivity) }\end{array}$ & 0.771 & & & \\
\hline $\begin{array}{l}\text { P5RPR (Absenteeism } \\
\text { effectivity) * }\end{array}$ & 0.662 & & 0.569 & \\
\hline $\begin{array}{c}\text { P7RPR (Training } \\
\text { effectivity) }\end{array}$ & & 0.876 & & \\
\hline $\begin{array}{l}\text { P1RCL (Clients direct } \\
\text { information) }\end{array}$ & & 0.808 & & \\
\hline $\begin{array}{c}\text { P2RCV (Key results no } \\
\text { econ-fin) }\end{array}$ & & 0.807 & & \\
\hline $\begin{array}{l}\text { P4RCV (KPIs. no } \\
\text { econ fin) }\end{array}$ & & 0.787 & & \\
\hline P3RCV (KPIs.econ.fin) & & 0.783 & & \\
\hline $\begin{array}{l}\text { P4RCL (Cause-effect } \\
\text { relationship) * }\end{array}$ & & 0.683 & 0.623 & \\
\hline $\begin{array}{l}\text { P3RCL (Complaints } \\
\text { and demands) ** }\end{array}$ & & 0.596 & 0.571 & \\
\hline $\begin{array}{l}\text { P6RPR (Performance } \\
\text { KPIs. vs. people } \\
\text { satisfaction) }\end{array}$ & & & 0.782 & \\
\hline $\begin{array}{l}\text { P5RCL (Thirds } \\
\text { compararations) }\end{array}$ & & & 0.742 & \\
\hline P2RCL (Image) ** & 0.525 & & 0.613 & \\
\hline $\begin{array}{l}\text { P1RCV (Key results } \\
\text { econ. fin) }{ }^{* * *}\end{array}$ & & & & 0.807 \\
\hline
\end{tabular}

Notes: $\mathrm{KMO}=0.693$; Explained variance $=74.5 \%$. ${ }^{*}$ The item is not kept in Version 2 of the questionnaire. ${ }^{* *}$ The item saturates by more than 1 factor. ${ }^{* * *}$ There is only 1 item for the factor. 
The joint exploratory analysis of feedback items is therefore distributed across the four latent factors mentioned above. The first factor consists of most items of Results in Persons and Society. The second factor brings together, mainly, items of Results in Clients, especially concerning their direct perception. The third factor collects items from Key Results of an organizational nature. Finally, a reference is made to the economic-financial results of direct impact on the previous results. The third factor is affected by the double saturation of some of the indicators, such as image, complaints, or cause-and-effect relationship analysis. The fourth only has a single indicator of financial-economic performance. Although both items are integrated in the conceptualization of the Key Results construct, the analysis performed suggests their separation.

Given the results of this exploration, the constructs that make up the dimension of Feedback could be established, starting in four main sections: Results in People and Society, Customer and Performance Results (non-economic), Learning and benchmarking, and Economic-financial results.

The hypotheses to be verified within the framework of the Feedback dimension that is the product of the relationship between latent constructs of all the Results Criteria are as follows:

Hypothesis 3a (H3a). The latent variables Results in People and Customer Results would covary to each other in a positive and meaningful way.

Hypothesis $3 \mathbf{b}(\mathbf{H} 3 \mathbf{b})$. The latent variables Customer Results and Key Results would covary to each other in a positive and meaningful way.

Hypothesis 3c (H3c). The latent variables Results in Society and Key Results would covary to each other in a positive and meaningful way.

Hypothesis 3d (H3d). The latent variables Results in People and Results in Society would covary to each other in a positive and meaningful way.

Figure 3 shows confirmatory analysis. Results indicate that all items saturate positively and significantly with the respective latent result variables. Table 2 then shows the detailed results and their statistical significance, along with the model adjustment indicators and covariance values to contrast the hypotheses raised.

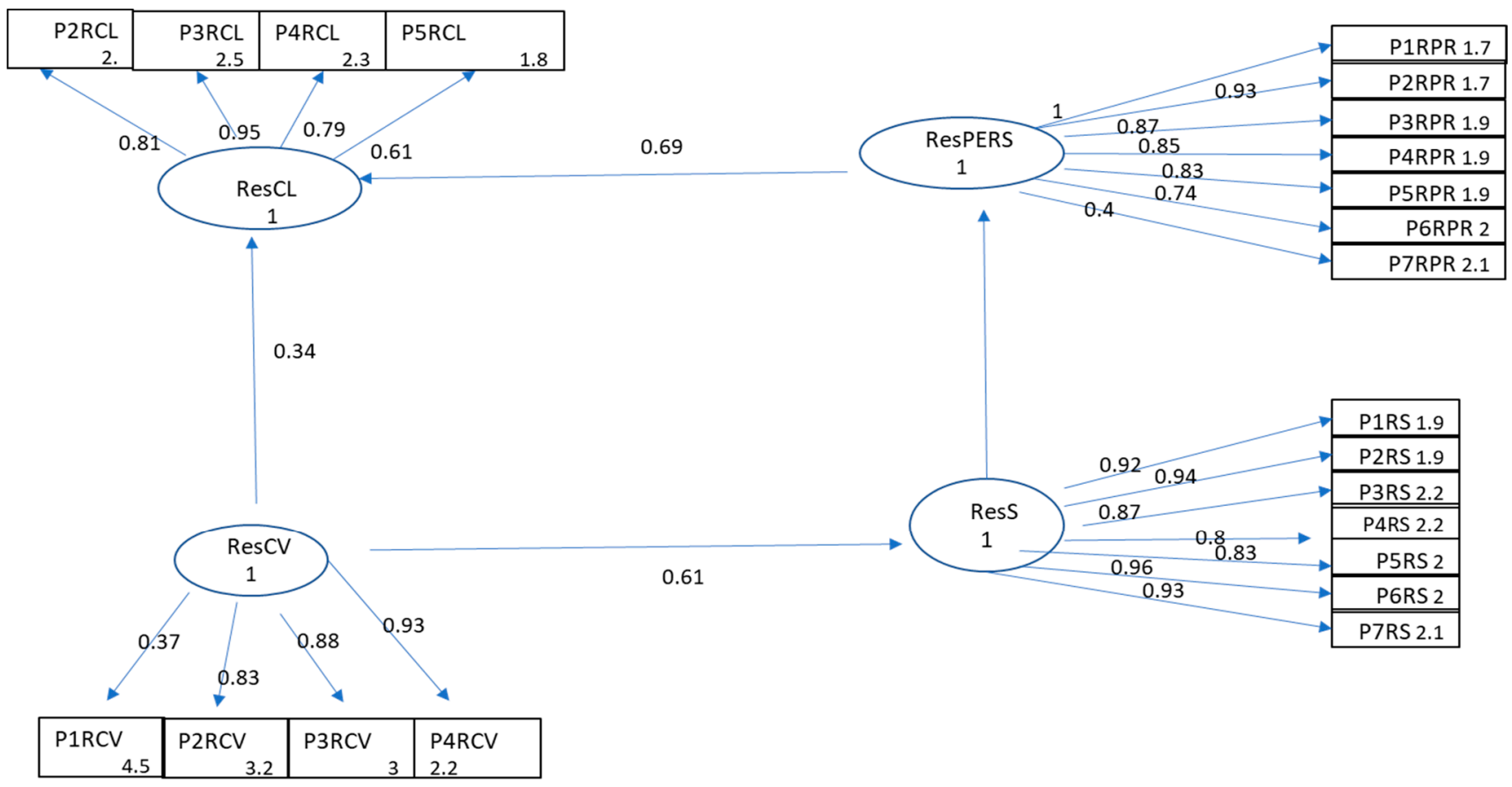

Figure 3. Confirmatory factorial analysis: Criteria results. Notes: ResPers = People Results; $\operatorname{ResCl}=\mathrm{Customer}$ Results; ResS = Society Results; ResCV = Key Results. 
Table 2. Confirmatory factorial analysis: Feedback results.

\begin{tabular}{|c|c|c|c|c|}
\hline Items & Coef. & $\mathbf{z}$ & $p>|\mathrm{z}|$ & IC \\
\hline P1RCL a ResCL & $0.78(0.074)$ & 10.56 & 0.000 & $0.68-0.94$ \\
\hline P2RCL a ResCL & $0.81(0.066)$ & 12.19 & 0.000 & $0.69-0.93$ \\
\hline P3RCL a ResCL & $0.94(0.033)$ & 28.47 & 0.000 & $0.88-0.99$ \\
\hline P4RCL a ResCL & $0.79(0.073)$ & 10.80 & 0.000 & $0.64-0.93$ \\
\hline P5RCL a ResCL & $0.61(0.073)$ & 5.42 & 0.000 & $0.39-0.83$ \\
\hline P1PR a ResPers & $0.99(0.006)$ & 152.71 & 0.000 & $0.98-1.00$ \\
\hline P2PR a ResPers & $0.97(0.009)$ & 101.18 & 0.000 & $0.95-0.99$ \\
\hline P3PR a ResPers & $0.86(0.044)$ & 19.37 & 0.000 & $0.77-0.99$ \\
\hline P4PR a ResPers & $0.85(0.048)$ & 17.78 & 0.000 & $0.76-0.95$ \\
\hline P5PR a ResPers & $0.83(0.055)$ & 14.94 & 0.000 & $0.72-0.94$ \\
\hline P6PR a ResPers & $0.73(0.083)$ & 8.85 & 0.000 & $0.57-0.90$ \\
\hline P7PR a ResPers & $0.40(0.14)$ & 2.72 & 0.007 & $0.11-0.69$ \\
\hline P1RS aResS & $0.91(0.033)$ & 27.74 & 0.000 & $0.85-0.98$ \\
\hline P2RS aResS & $0.93(0.027)$ & 34.05 & 0.000 & $0.68-0.97$ \\
\hline P3RS aResS & $0.87(0.044)$ & 19.71 & 0.000 & $0.78-0.93$ \\
\hline P4RS aResS & $0.80(0.065)$ & 12.29 & 0.000 & $0.67-0.95$ \\
\hline P5RS aResS & $0.83(0.056)$ & 14.89 & 0.000 & $0.72-0.94$ \\
\hline P6RS aResS & $0.95(0.020)$ & 47.16 & 0.000 & $0.91-0.99$ \\
\hline P7RS aResS & $0.93(0.027)$ & 39.02 & 0.000 & $0.87-0.98$ \\
\hline P1RCV aResCV & $0.37(0.155)$ & 2.39 & 0.017 & $0.06-0.67$ \\
\hline P2RCV aResCV & $0.82(0.062)$ & 13.25 & 0.000 & $0.78-0.98$ \\
\hline P3RCV aResCV & $0.88(0.051)$ & 17.23 & 0.000 & $0.78-0.98$ \\
\hline P4RCV aResCV & $0.93(0.08)$ & 22.60 & 0.000 & $0.84-0.99$ \\
\hline H3a cov (ResCL, ResPer) & $0.69(0.10)$ & 6.66 & 0.008 & $0.48-0.89$ \\
\hline H3b cov (ResCL, ResCV) & $0.34(0.12)$ & 2.64 & 0.000 & $0.08-0.59$ \\
\hline H3c cov (ResS, ResCV) & $0.61(0.12)$ & 4.75 & 0.000 & $0.35-0.85$ \\
\hline H3d cov (ResPers, ResS) & $0.65(0.10)$ & 6.50 & 0.000 & $0.79-0.96$ \\
\hline Model fit & 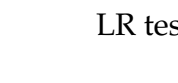 & $\begin{array}{l}\text { del vs } \\
\text { Prob }\end{array}$ & $\begin{array}{l}\text { ed: chi2 } \\
0.0000\end{array}$ & 77 , \\
\hline
\end{tabular}

Notes: $p>|z|=0.000$ statistically significant at a level $<1 \%$. The maximum variance of the latent variables is fixed at the unit.

The results of the confirmatory analysis show that the four hypotheses raised are met and that there is a statistically significant relationship between Customer Results and People Results (0.69), Customer Results and Key Results (0.34), Company Results and Key Results (0.61), and Results in Persons and Company Results (0.65).

The verification of the hypotheses in the confirmatory analysis highlights that, although this has been carried out according to the relationships between items and constructs as proposed in the 2003 and 2010 versions of the EFQM, the conclusions of the factor analysis of all items together coincide. It is confirmed that the relationship among the People Results, Company Results, and Client Results items tends to interfere by saturating between one and two factors, while Key Results would require a clearer split between economic-financial results and the other factors. As a synthesis, the new four latent constructs (Results in People and Society, with a special focus on perception, Customer, and performance outcomes and not economic-financial results, Learning and benchmarking, and Financial Economic Results) would form a second-degree factorial to obtain the dimension of Feedback 


\section{Discussion}

Table 3 details the summary of hypothesis verification on the evolved EFQM Model, with the adequacy of orientation, action, and feedback dimensions as second-degree factors.

Table 3. Hypothesis verification: Simplified research model.

\begin{tabular}{cc}
\hline Proposed Hypotheses (Theoretical Relationships) & Empirical Verification \\
\hline H1 covariance (Leadership and Strategy) & $\mathrm{Ok}$ \\
\hline H2 covariance (People, Resources and Processes) & $\mathrm{Ok}$ \\
\hline H3 covariance (all results criteria) & $\mathrm{Ok}$ \\
\hline H3a covariance (ResCL y ResPer) & $\mathrm{Ok}$ \\
\hline H3b covariance (ResCL y ResCV) & $\mathrm{Ok}$ \\
\hline H3c covariance (ResS y ResCV) & $\mathrm{Ok}$ \\
\hline H3d covariance (ResPers y ResS) & $\mathrm{Ok}$ \\
\hline
\end{tabular}

The constructs associated with Results in Clients, Persons, Company, and Key can be summarized in a single factor called Feedback after reviewing the combinations of the items between constructs and the possible grouping of these as follows: (1) Results in Persons and Society; (2) Results in Clients and performance (non-economic); (3) Learning and benchmarking results; and (4) Economic-financial results. The confirmation of all the hypotheses regarding the Feedback construct makes it possible to propose an evolved second-degree EFQM model based on the following aspects:

1. Leadership and Strategy constructs, after confirming a strong relationship between these latent variables, can be presented as a single second-degree factor named Guidance without the contrast of this hypothesis implying some alterations in the items that it consists of.

2. The constructs of People, Alliances and Resources, and Processes can be presented in a single latent second-degree factor named Action. Taking into account the inputs of the exploratory analysis, the constructs that would make up this factor could be grouped as follows: (1) Involvement and commitment of people; (2) Management of change and creation of value; and (3) Management and Transformation Model.

\section{Conclusions and Future Lines of Research}

The analysis has aimed to suggest a simplified proposal of the EFQM model, which has been achieved by verifying the high levels of correlation between criteria, as well as between the items that make them up, resulting in an improved configuration of these criteria.

\subsection{Theoretical Contribution}

This study is intended to contribute to the existing literature in terms of adopting a holistic perspective of the EFQM model beyond a set of elements or management areas. This perspective, paradoxically, has not been adopted as widely as might be assumed, contributing to a lack of theory on the approach that remains to this day [3].

After the analysis carried out, Table 4 contrasts the parallelism between the new criteria of the evolved EFQM model and the structure of the EFQM 2020 model. 
Table 4. Parallelism between dimensions after confirmation factorial analysis.

\begin{tabular}{|c|c|c|c|}
\hline & Evolved EFQM Model & & EFQM Model 2020 \\
\hline \multirow{5}{*}{ Feedback } & Results in People and Society & \multirow{5}{*}{ Results } & \multirow{3}{*}{ Stakeholders' perceptions } \\
\hline & Results in Clients and Performance & & \\
\hline & Management (no economics) & & \\
\hline & Learning and benchmarking results & & \multirow{2}{*}{$\begin{array}{l}\text { Strategic and Operative } \\
\text { Performance }\end{array}$} \\
\hline & Economic-Financial Results & & \\
\hline
\end{tabular}

\subsection{Research Contribution}

The hypotheses on which the evolved EFQM model is based, which is open to verification in future research that contrast the reduction of constructs in three second-degree dimensions, are as follows:

Hypothesis 4 (H4). There is a positive and one-way impact from Direction (the first aggregate dimension of the EFQM 2020 Model) as a latent construct towards Feedback in the evolved EFQM Model.

Hypothesis 5 (H5). There is a positive and one-way impact from Execution (second aggregate dimension of the EFQM 2020 Model) as a latent construct towards Feedback in the evolved EFQM Model.

Hypothesis 6 (H6). Management not only directly influences Results (the third aggregate dimension of the EFQM 2020 Model) but also indirectly and positively through the implementation moderating effect.

\subsection{Implications for Management}

The level of grouping of the EFQM model in three dimensions (Guidance, Action, and Feedback) can be very useful from a management perspective, as it more easily articulates the areas in which management teams approach decision-making from three different perspectives: from a strategic point of view (Guidance), determining the direction in which the organization is to move; from a tactical point of view (Action), articulating the different elements and resources available and mobilizing them to achieve the objectives envisaged; or from an operational point of view (Feedback) through a comprehensive and global system of monitoring indicators that allow to contrast the degrees of progress and redirect to the organization if appropriate. Although the application of this EFQM model is perfectly generalizable to any sector that aspires to excellence in management, this is particularly relevant in the case of a public transport company and, in this way, our case study could be considered as a guide for other academics and practitioners in the application of this model to different sectors. This situation is common internationally, where the need to manage companies with outstanding results becomes a challenge. These are organizations with public funding, a demand for high levels of service quality that include safety, punctuality, and sustainability as key elements, and also compete with the air and land sectors. This challenge contributes to the need to bet on different organizational models based on a holistic purpose and articulated through strategy and leadership.

It is essential to strengthen the role of the public manager in terms of the elements on which they are to base their management function, concerning not only the assurance of efficiency in the management of public resources [22,23], but also in regard to the establishment of a purpose [24] that brings together the aspirational goals of the collective of people who make up the organization and society as a whole, thus activating mechanisms that ensure the cooperation and involvement of all.

On the other hand, the fact that all the hypotheses raised have been confirmed in terms of the grouping and the simplification of the EFQM model's criteria from nine areas to three is a particularly relevant finding because it is the first time that an investigation empirically refutes this approach in its entirety, which, in turn, helps to further advance 
the construction of the theory associated with the Models of Excellence and the EFQM model in particular. This advancement is relevant not only from an academic perspective but also from a practical perspective: the use of the evolved EFQM model as an evaluation tool can be complemented by the use of the model as a transformation and management support tool.

This process highlights the need for management teams to continuously seek new ways of thinking, planning, and acting in an environment in which successful management practices will be quickly imitated by third parties, nulling the potential initial competitive advantage. It is also key to note that the more systemic the adoption of the EFQM model, the more successful the organization will be [25].

Currently, the EFQM model does not provide many organizations with a sufficiently explicit adoption and adaptation guide to help management teams adopt the deployment to their particular circumstances and degree of organizational maturity. The proposed framework aims to deepen this aspect, giving organizations a more explicit sequence of interventions.

Finally, the potential use of the EFQM model is as a structured tool to assess the degree of goodness of any business or activity model that may be of particular interest to management teams. While there has been no broad consensus in the academic literature on the concept of business models, its conception has its origins in the 1950s [26], and a meta-analysis of definitions published between 1989 and 2002 [27] identifies four common categories between them all: strategic choices, value creation, value capture, and value network. Beyond the crucial relevance of these elements and their interrelationships, one of the most global definitions in this regard is that of a "set of choices made by the organization and set of consequences that derive from such elections" [28]. This definition's two main elements, choices and consequences, coincide with the large blocks that make up the EFQM model: Criteria Facilitator Agents and Criteria Results, or Guidance, Action, and Results, and Feedback (EVOLVED EFQM model).

The sustained success of any business model lies in deeply understanding the causeand-effect relationship between what an organization does and what an organization obtains, not only from a historical (past) point of view but, most importantly, from a future perspective (i.e., sustainability, a key concept of success as understood throughout this research).

Author Contributions: Conceptualization, J.R.G.-A. and R.O.-L.; investigation, J.R.G.-A., R.O.-L. and J.B.-O.; data curation, J.R.G.-A., R.O.-L. and J.B.-O.; writing-original draft preparation, J.R.G.-A., R.O.-L. and J.B.-O.; funding acquisition, J.R.G.-A., R.O.-L. and J.B.-O. All authors have read and agreed to the published version of the manuscript.

Funding: This research was funded by the Regional Government of Aragón (Grant S32_20R).

Institutional Review Board Statement: Not applicable.

Informed Consent Statement: Not applicable.

Conflicts of Interest: The authors declare no conflict of interest.

\section{References}

1. García Aranda, J.R. Gestionar el cambio con agilidad. El Modelo EFQM y su actualización 2013 (Parte I). Certificación Alta Dir. Excel. 2013, 59, 78-79.

2. Friedman, M. The social responsibility of business is to increase its profits. N. Y. Times Mag. 1970, $33,126$.

3. Kim, D.Y.; Kumar, V.; Murphy, S.A. European Foundation for Quality Management (EFQM) Business Excellence Model: A Literature Review and Future Research Agenda; Sprott School of Business, Carleton University: Halifax, NS, Canada, 2008.

4. Conti, T. Organizational Selfassessment; Chapman \& Hall: London, UK, 1997.

5. Bou-Llusar, J.C.; Escrig-Tena, A.B.; Roca-Puig, V.; Beltrán-Martín, I. To what extent do enablers explain results in the EFQM excellence model? Int. J. Qual. Reliab. Manag. 2005, 22, 337-353. [CrossRef]

6. Bou-Llusar, J.C.; Escrig-Tena, A.B.; Roca-Puig, V.; Beltrán-Martín, I. An empirical assessment of the EFQM Excellence Model: Evaluation as a TQM framework relative to the MBNQA Model. J. Oper. Manag. 2009, 27, 1-22. [CrossRef] 
7. Heras, I.; Marimon, F.; Casadesús, M. An empirical study of the relationships within the categories of the EFQM model. Total Qual. Manag. Bus. Excell. 2012, 23, 523-540. [CrossRef]

8. Kristensen, K.; Juhl, H.J. Beyond the bottom line-Measuring stakeholder value. In The Nordic School of Quality Management; Edvardsson, B., Gustafsson, A., Eds.; Studentlitteratur: Lund, Sweden, 1999.

9. Abdullah, M.; Hamid, M.R.A.; Mustafa, Z.; Husain, N.; Idris, F.; Suradi, N.R.M.; Ismail, W.R. Value-based total performance excellence model: A conceptual framework for organisations. Total Qual. Manag. Bus. Excell. 2012, 23, 557-572. [CrossRef]

10. Campatelli, G.; Citti, P.; Meneghin, A. Development of a simplified approach based on EFQM Model and Six Sigma for the implementation of TQM principles in a university administration. Total Qual. Manag. Bus. Excell. 2011, 22, 691-704. [CrossRef]

11. Asif, M.; Searcy, C.; Garvare, R.; Ahmad, N. Including sustainability in business excellence models. Total Qual. Manag. Bus. Excell. 2011, 22, 773-786. [CrossRef]

12. Mohammad, M.; Mann, R.; Grigg, N.; Wagner, J.P. Business Excellence Models: An overarching framework for managing and aligning multiple organisational improvement initiatives. Total Qual. Manag. Bus. Excell. 2011, 22, 1213-1236. [CrossRef]

13. Lu, D.; Betts, A.; Croom, S. Re-investigating business excellence: Values, measures and a framework. Total Qual. Manag. Bus. Excell. 2011, 22, 1263-1276. [CrossRef]

14. Eskildsen, J.K.; Dahlgaard, J.J. A causal model for employee satisfaction. Total Qual. Manag. 2000, 11, 1081-1094. [CrossRef]

15. Eskildsen, J.K.; Kristensen, K.; Juhl, H.J. The causal structure of the EFQM Excellence Model. In Conference Proceedings; MAAOE: Estes Park, CO, USA, 2000. Available online: https:/ / pure.au.dk/portal/files/32330561/0003106.pdf (accessed on 3 June 2021).

16. Sadeh, E.; Arumugam, V.C. Interrelationships among EFQM excellence criteria in Iranian industrial SMEs. Eur. J. Econ. Financ. Adm. Sci. 2010, 19, 155-167.

17. Calvo-Mora, A.; Leal, A.; Roldán, J. Using enablers of the EFQM model to manage institutions of higher education. Qual. Assur. Educ. 2006, 14, 99-122. [CrossRef]

18. Lowe, K.B.; Kroeck, K.G.; Sivasubramaniam, N. Efectiveness correlates of transformational and transactional leadership: A meta-analytic review of the MLQ literature. Leadersh. Q. 1996, 7, 385-425. [CrossRef]

19. Heise, D.R. Causal Analysis; John Wiley \& Sons: New York, NY, USA, 1975.

20. Satorra, A.; Bentler, P.M. Scaling corrections for chi-wquare statistics in covariance structure analysis; In Proceedings of the American Statistical Association 1988 Proceedings of Business and Economics Sections; American Statistical Association: Alexandría, Egypt. 1988, pp. 308-313. Available online: https:/ / escholarship.org/uc/item/3141h70c (accessed on 3 June 2021).

21. Bollen, K.A. A nes incremental fit index for general structural equation models. Sociol. Methods Res. 1989, 17, 303-316. [CrossRef]

22. Aberbach, J.D.; Putnam, R.D.; Rockman, B.A. Bureaucratics and Politicians in Western Democracies; Harvard University Press: Cambridge, MA, USA, 1981.

23. Peters, T.J.; Waterma, R.H. (Eds.) In Search of Excellence; Harper and Row: New York, NY, USA, 1982.

24. Barnard, C.I. The Functions of the Executive, Rev ed.; Harvard University Press: Cambridge, MA, USA, 1968.

25. Paauwe, J.; Boselie, P. Best practices... in spite of performance: Just a matter of imitation? Int. J. Hum. Resour. Manag. 2005, 16, 987-1003. [CrossRef]

26. Drucker, P. The Practice of Management; Harper Business: New Yourk, NY, USA, 1954.

27. Shafer, S.M.; Smith, H.J.; Linder, J.C. The power of business models. Bus. Horiz. 2005, 48, 199-207. [CrossRef]

28. Ricart, J. Modelo de Negocio: El eslabón perdido en la dirección estratégica. Universia Bus. Rev. 2009, $23,12-25$. 